\section{SDI snubs APS}

\section{Washington}

The Strategic Defense Initiative Organization (SDIO) delivered a public snub to the American Physical Society (APS) recently by boycotting at the last minute a symposium on strategic defence at APS's spring meeting in Washington. According to Richard Bleach, one of two invited speakers from SDIO who failed to turn up at the meeting, SDIO senior management decided that "some of the abstracts for the session were so political that we should find some other place to present [our results]".

Bleach, who works in the SDIO programme integration office, had been due to represent SDIO together with James Ionson, head of SDIO's innovative science and technology office. The title for the session was "Impacts of the Strategic Defense Initiative on the physics community". In addition to speaking at the symposium, Bleach and Ionson had been due to appear at an APS press conference.

Ionson let APS know in advance that he would not attend the press conference, but, according to Robert Park of APS, no word was received that he also would not appear at the symposium. Ionson says it would be improper for him to appear at someone else's press conference without approval from SDIO management, which was apparently not sought; he says he asked his office to let APS in New York know that he would not attend.

Bleach told APS he would not attend the symposium or the press conference on the day they were to occur. Bleach says he was told by senior SDIO management not to attend the session after they read published abstracts of other talks to be given at the symposium: one, by Charles Schwartz of the University of California at Berkeley, states: "The strategic defense initiative... will push strategic instabilities so far that it will be difficult, in a time of severe crisis, for national leaders to avoid the option of pre-emptive attack". Schwartz goes on to say that "this is the career awaiting the major portion of our physics students" and proposed to discuss "several forms of resistance".

SDIO has other reasons to be irritated with APS besides the allegedly "political" meeting. The society has recently given much publicity to an opinion poll of its members which found almost a two-to-one majority believing SDI was bad for national security.

Anti-SDI feeling was certainly prevalent at the Washington meeting: an official desk was promoting anti-SDI literature. At the ill-fated press conference, representatives of Fusion magazine, a publication linked to political maverick Lyndon LaRouche, castigated APS for not giving similar space to non-governmental supporters of the Strategic Defense Initiative. Tim Beardsley

US in space

\title{
Delta failure a big set-back
}

\section{Washington}

THE spate of calamities that has struck the US space programme this year has led the National Aeronautics and Space Administration (NASA) into difficulties both with the Office of Management and Budget and with Congress. Damaging revelations continue to surface about slipshod safety procedures that may have contributed to the explosion on 28 January of the space shuttle Challenger and, most recently, the failure on 3 May of an unmanned Delta rocket at Cape Canaveral.

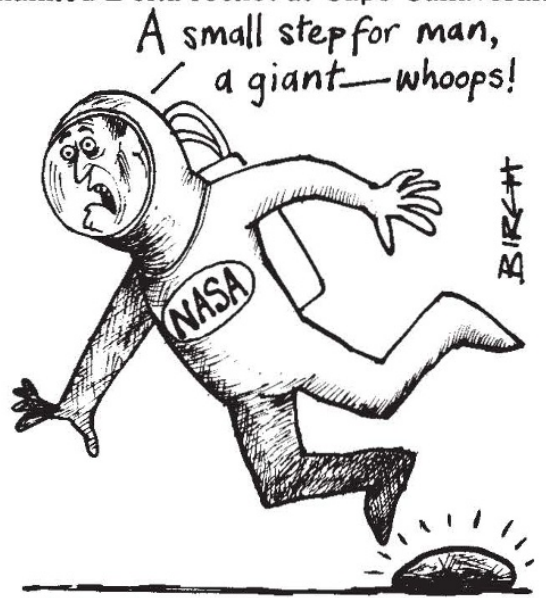

Meanwhile, a proposal to provide NASA with funds for a replacement shuttle orbiter remains stalled in the White House.

The accident on 3 May, in which a Delta launcher and a National Oceanic and Atmospheric Administration weather satellite (GOES-7) were destroyed following a rocket engine failure, means that the United States now has no reliable means of launching payloads of over 2,000 lb into orbit, at least until the causes of the recent accidents have been determined and corrective measures taken.

NASA had planned to launch three more Deltas for paying customers (one more weather satellite and two Strategic Defense Initiative experiments) before turning the rocket over to the private sector; the accident will only strengthen the resolve of the US Air Force to expand its independent launch capability, and distance itself from the administration's previous policy of relying exclusively on the shuttle for military access to space.

There are some 17 Atlas rockets of different types available for military use, most already assigned to a launch. But because of similarities between the Delta engine and that of the Atlas rocket, Atlases are also grounded until the Delta problem is tracked down.

Meanwhile, the Air Force has its own problems, with the explosion (also last month) of a Titan 34D rocket seconds after lifting off from Vandenberg Air Force base in California. In response to the shuttle loss and the Titan accident, the Air Force is to procure 13 additional Complementary Expendable Launch Vehicles (CELVs), otherwise the Titan 34D7. These will be extra to the 13 Titan-2s being refurbished for Air Force use.

NASA has still not prepared a detailed supplementary budget request for fiscal year 1987 in the light of the Challenger and other accidents, which is becoming the source of some frustration on Capitol Hill. NASA officials say they are convinced of the need for a new orbiter, but a decision on who should pay for it apparently still not been settled, with the Office of Management and Budget opposing the use of extra funds.

The total cost of a new orbiter, modifying the suspect solid booster joint on the other orbiters and the replacement of spare parts, comes close to $\$ 3,000$ million, so if NASA had to find the cost of a new orbiter out of its own budget it would be able to do very little else for a year.

Part of the argument now hinges on whether the cost of a new shuttle could be justified as a national security emergency; if it could be, it need not be included in the deficit reduction target of the GrammRudman law. An administration decision is expected next month.

A further difficulty is that NASA has not yet published a proposed plan for dealing with the backlog of shuttle launches once they do begin again, which is now thought unlikely before July 1987 . As about 16 launches per year had been planned, the backlog is likely to be around 24 . Given that military payloads will have priority over others, it seems clear that scientific missions will be greatly delayed. One suggestion is that the Galileo mission to Jupiter would take a "delta vega" trajectory via the inner planets, which would take two years longer than the original trajectory, but would eliminate the narrow launch window that puts Galileo in competition for a slot with Ulysses, the joint mission with West Germany to the poles of the Sun.

There remain several important safety hurdles to be negotiated. The Centaur upper stage used in these missions would be the first liquid-fuelled upper stage to fly in the shuttle, and special safety reviews of the issue have been instituted. The intended use in the spacecraft of radioactive thermal generators has only added to nervousness about the consequences of another shuttle accident.

Commercial satellite launches have also been held up by the shuttle accident, and Arianespace, the competing French carrier, has taken some extra bookings. The order books are now full until 1989, and Arianespace says it cannot greatly in- 
crease its launch rate. China is eager to fill the breach, and according to China Daily, the two satellites retrieved from faulty orbits by the shuttle will be the first commercial launches in China's Long-March3 rocket. The launches are scheduled for 1987.

Meanwhile NASA officials have to face the music over the sudden change in the agency's fortunes. NASA's director for space flight, Rear Admiral Richard Truly, was taken to task last week by Senator Albert Gore (Democrat, Tennessee) over reductions in the number of NASA reliability and quality assurance personnel. According to Gore (relying on documents leaked by a NASA employee), these averaged 71 per cent across the agency over 15 years, as compared with a 30 per cent reduction in the size of the agency as a whole. Gore concluded that NASA, which was already drifting, "is now drifting further".

Tim Beardsley

Tropical diseases

\section{More research, more money?}

A LEANER management and a fatter programme of basic and clinical research are planned for the Special Programme for Research and Training in Tropical Diseases (TDR) by its new director, Dr Tore Godal. When he takes over next month, initially for two years, from Dr Adetokunbo Lucas, Godal does so with the prospect of an increasing budget for TDR, which is financed by the United Nations Development Programme, the World Bank, the World Health Organization and individual countries.

Chief among the donating countries are the United States, Sweden, Denmark and Norway, from which Godal comes. The Scandinavians have always been generous towards TDR, says Godal, and there is a good chance that they will become even

\section{Tokyo summit}

\section{Nakasone disappointed}

\section{Tokyo}

OTHER than the Chernobyl incident, little attention was given to science and technology issues at the summit although appreciation was officially recorded for the continuing efforts at the international series of "biology and ethics" meetings instigated by Prime Minister Yasuhiro Nakasone (see Nature 308, 395; 1984). That discussion of ethics has been the sole outcome of the numerous international technology research projects put forward at successive summits is some indication of the difficulty of international cooperation outside basic science.

Conspicuous by its absence at this year's summit was the "Human Frontier Project". Thought up by Japan's Ministry of International 'Trade and Industry (MITI), the project for large-scale research in biology (Nature 320, 296; 1986) with application in mind was not presented at the summit as had been hoped. Officials from MITI have toured major Western nations to explain the project, but lack of clear details and an assured budget have so far elicited only polite encouragement. Whether anything more will come of it now depends on whether Japan's Ministry of Finance can be persuaded to put up funds on a scale sufficient to support research abroad as well as in Japan, an entirely new idea to the ministry.

During the summit, Nakasone's mind may well have been on a quite different kind of technological development - the increasingly sophisticated mortars developed by the extreme left-wing organization Chukakuha. Repeated rumours that the Chukakuha had developed mortars with a range of up to $4 \mathrm{~km}$.

As it was, the rumours turned out to be correct: during the summit welcome ceremony, five mortar shells were fired from an apartment $2.5 \mathrm{~km}$ from the summit building. All overflew the main venue and landed up to $500 \mathrm{~m}$ beyond it. The new mortars have an estimated range of $3.7 \mathrm{~km}$, up from the $2-\mathrm{km}$ range mortars used in an attack on airports earlier this year and from the $1-\mathrm{km}$ range mortars used last year. Regardless of political views, it seems that rapid technological improvement is a Japanese trait. So far no damage, other than psychological, has been done by the mortars.

Mrs Margaret Thatcher's excellent spirits were evident at the end of the summit which she summed up with "mission accomplished". Among the leaders perhaps only Nakasone was left disappointed. He is now under attack for failing to obtain any action to halt the extraordinarily rapid rise of the yen. The most important decision made at the summit was undoubtedly that of creating a "Group of Seven" finance ministers which will meet frequently to examine the mutual compatibility of their economic policies.

Nakasone also found himself under fire for having agreed to a summit statement on international terrorism which specifically names Libya as a supporter of terrorism. Until now, Japan has managed to stand aside from the problems of the Middle East, doing business with everyone and selling arms to nobody. Many Japanese do not relish lining up with the Western nations and facing possible terrorist action. But both this and the acceptance of cooperative economic policies may also be seen as the inevitable emergence of Japan as a big power.

Alun Anderson more so. He would also like to persuade the United States and Britain to increase their contributions. Both take more money from TDR than they contribute. although there the similarity ends; at $\$ 2.0$ million, the US contribution was 10 per cent of the total annual budget, larger than that of any other country, whereas the UK contribution, which surpassed $\$ 1.3$ million in 1979 , was cut to zero in 1982 and was $\$ 0.3$ million in 1985 .

Godal would like TDR to spend more on basic aspects of parasite biology, preparing the way for new approaches to chemotherapy and vaccination, and on field research into TDR's target diseases. malaria, schistosomiasis, filariasis, leprosy. leishmaniasis and trypanosomiasis. If no more money is forthcoming, this will have to be at the expense of clinical research and the blind screening of candidate drugs. For the time being. TDR's income in terms of US dollars is increasing as a result of the fall in the value of the dollar against the currencies of many donor countries.

Malaria remains the top priority of TDR's diseases. particularly with the growing problem of resistance of malaria parasites to drugs, whereas priorities among the other five diseases will continue to change with circumstances. In recent years and with growing signs of success, TDR has spent an increasing portion of its budget on research into leprosy, the subject of Godal's own research in Oslo and with Ethiopian collaborators.

Godal views with some anxiety a proposal, to be considered by the board of TDR in June, to allow donor countries to earmark a proportion of their contribution for research on particular diseases. If implemented, this could mean that it was not scientific criteria alone that would determine what was funded, and it is the strength of its science that has accounted for TDR's past success in Godal's view.

He is less anxious about the problem of relationships with industry. While there is often a conflict of interest between donors and the pharmaceutical companies that are needed for the large-scale production of any products of TDR research. Godal considers that some of these problems have been smoothed out by experience and that ad hoc solutions will be possible.

With regard to administration and management, Godal's plan is for simplification. Application will be less hierarchical, and less staff will be needed.

Godal will continue to look after his doctoral students in Oslo but will otherwise devote himself wholly to TDR. He starts in Geneva on 9 June: Lucas leaves on 1 July to start working for the Carnegie Institute in New York. Peter Newmark 